Mohnen, S.M., Völker, B., Flap, H., Subramanian, S.V., Groenewegen, P.P. The influence of social capital on individual health: is it the neighbourhood or the network? Social Indicators Research: 2015, 121(1 SI), 195-214

\begin{tabular}{|l|l|}
\hline $\begin{array}{l}\text { Postprint } \\
\text { Version }\end{array}$ & 1.0 \\
\hline Journal website & http://link.springer.com/article/10.1007/s11205-014-0632-8 \\
\hline Pubmed link & \\
\hline DOI & $10.1007 / s 11205-014-0632-8$ \\
\hline
\end{tabular}

This is a NIVEL certified Post Print, more info at http://www.nivel.eu

\title{
The Influence of Social Capital on Individual Health: Is it the Neighbourhood or the Network?
}

\author{
SIGRID M. MOHNEN • BEATE VÖLKER • HENK FLAP • S. V. SUBRAMANIAN •PETER P. \\ GROENEWEGEN
}

\begin{abstract}
We examined the influence of both individual and neighbourhood social capitalon individual health and analysed whether effects of one type of social capital are contingent upon the other. The Dutch 'Housing and Living Survey' (WoON 2006, $\mathrm{n}=53,269$ ) was used and combined with information on neighbourhoods ( $\mathrm{n}=3,273)$.

Using an ecometric approach to estimate neighbourhood social capital, we found that both types of capital were associated with health. In addition, those who have only few contacts with friends and relatives have nevertheless a good health if they have much neighbourhood social capital. The findings demonstrate the potential importance of both types of social capital and the possibility of compensation of one type of social capital by the other one.
\end{abstract}

\section{BACKGROUND}

Previous research on the association between neighbourhood social capital and health has not taken into account social capital on the micro level, i.e. an individual's social capital(Moore et al. 2006). Neglecting this type of social capital risks finding spurious effects on individual social capital instead of a 'true' neighbourhood effect at community level. More generally, it does not take into account that social capital has effect on multiple levels, the macro level of neighbourhoods and the micro level of the individual as well (Kawachi andSubramanian 2006; Kawachi et al. 2008; Subramanian et al. 2003). Individual social capital is an individual's resources that are embedded in the relationship with specific others (House 1981; Lin et al. 1979). On the other hand, social capital at the neighbourhood level is defined by community resources such as, common norms, general reciprocity expectations and mutual trust (Putnam et al. 1993). These resources emerge from cohesion in a neighbourhood. ${ }^{1}$ An individual's actual network is not necessarily related to this community resource. In this study, we test both the independent and interrelated effects of individual and neighbourhood social capital on individual health. 
Mohnen, S.M., Völker, B., Flap, H., Subramanian, S.V., Groenewegen, P.P. The influence of social capital on individual health: is it the neighbourhood or the network? Social Indicators Research: 2015, 121(1 SI), 195-214

\subsection{The Association Between Neighbourhood and Individual Level Social Capital: Accumulation or Compensation?}

Neighbourhood social capital is defined by Coleman (1990) as a public good, which can be' consumed' by all residents of the neighbourhood regardless of whether or not they have contributed to its creation. Coleman provides an example of neighbourhood social capital in relation to feeling safe-in neighbourhoods with high social capital it is 'possible for women to walk freely outside at night' (op. cit.:310). It is not necessary to have individual relationships to benefit from these macro conditions.

How does neighbourhood social capital influence health? And can this be independent of a person's network? One possible explanation for the relationship is the higher level of social control-also concerning health related behavior-in closeknit neighbourhoods (Hystad and Carpiano 2010; Mohnen et al. 2012). Furthermore, a well-connected neighbourhood might be able to lobby more effectively for a green neighbourhood (Maaset al. 2008), which is amenable to walking (Sundquist et al. 2011), for healthy food(Shaw 2006) or access to healthcare (Hendryx et al. 2002). Finally, a psycho biological pathway is also possible: the feeling of 'belonging to a (friendly) community' might improve health. While these arguments point at different mechanisms, they have in common that a neighbourhood factor is associated with an individual's health without involving individual ties.

The aim of this contribution is to investigate the association between neighbourhood social capital, individual social capital and an individual's health. So, we do not focus on the explanatory mechanisms behind the effects of social capital, but on the interrelation of both types, which should be established in a first step.

Social capital theory assumes that the more social capital an individuals have the better they can achieve their goals in life. ${ }^{2}$ Consequently, our first hypothesis reads: The more social capital in a neighbourhood, the better the health of its residentsindependent of individual social capital. (Hy1)Similarly, the argument regarding individual social capital predicts that an individual's health is positively affected by his or her network, regardless of the neighbourhood in which s/he lives. It has been argued that individual social capital has both a direct effect and a buffering effect on individual health (Hammer 1983). Individuals with more social capital are less often ill and when they do fall ill they are better able to cope with diseases. Coping strategies refer to behavioural and psychological efforts that people employ to master, tolerate, reduce, or minimise stressful events (Taylor and Seeman 1999; Tijhuiset al. 1995). Some positive effects of social support (emotional support, informational support and instrumental support) work without individuals being aware of it. Uchino et al.

(1996) show that greater social support is associated with better immune system functions and benefits the endocrine and cardiovascular systems (e.g. blood pressure) as well as decreasing the likelihood of coronary artery diseases, susceptibility to infectious diseases and atherosclerosis (Diez-Roux and Mair 2010; Diez-Roux et al. 1997; Stockdale et al.

2007; Taylor et al. 1997).

In line with these arguments and results we expect the above mentioned main effect for individual-level social capital. The more individual-level social capital, the better the individual-level health—independent of neighbourhood-level social capital. 
Mohnen, S.M., Völker, B., Flap, H., Subramanian, S.V., Groenewegen, P.P. The influence of social capital on individual health: is it the neighbourhood or the network? Social Indicators Research: 2015, 121(1 SI), 195-214

(Hy2) Note that in both hypotheses it is assumed that one type of social capital, individual or collective, has an effect on health, independent of the other. How are neighbourhood and individual social capital related to each other? As both types of social capital are expected to be positively related to an individual's health, a lack of one type of social capital may be compensated by the other one. A person who has few social ties might nevertheless feel part of a close-knit community and therefore have good health. In a qualitative study on the heat wave of 1995 in Chicago, Klinenberg (2002)found that socially isolated people were better off in a close-knit community. In accordance with this finding, we argue that having higher community social capital can compensate for a lack of individual social capital. Hence, our compensation-hypotheses is as follows: Individuals who lack individual social capital but live in high social capital neighbourhoods have access to more health benefits than those who live in low social capital neighbourhoods.

(Hy3)However, one can also argue that it is possible that both types of social capital are conditional upon each other. In other words, one need a certain type of social capital to access another one. It might be that an individual needs to have social ties in order to be able to access to community resources. Carpiano (2007) discussed a person's access to resources by using Bourdieu's social capital theory and developed a model to explain how health is affected by social capital. Carpiano's research on social capital focuses on network ties in neighbourhoods (2007, 2008). He hypothesised that a personal network provides access to neighbourhood-level social capital (Carpiano 2007; Lin 2001). Consequently, the more personal contact a person has with others in their neighbourhood, the stronger the spread of neighbourhood norms and the greater the person's access to neighbourhood-level resources (Moore et al. 2011). In addition, social control of health related behaviour might be more effective when an individual has a number of social ties. Underage drinking, for instance, is more likely to be stopped in a close-knit neighbourhood; if neighbours know the parents of the underage drinker then the punishment can beharder and more effective.

Alongside neighbours, family members and friends living outside the neighbourhood can also help access to neighbourhood resources. For example, individual social capital might interact with local health care utilisation (Nauenberg et al. 2011). These arguments lead to another hypothesis, an accumulation hypothesis, which is in opposition to the compensation hypotheses formulated above: The effect of neighbourhood social capital on health is greater the higher the individual-level social capital. (Hy4)

\subsection{Evidence on Neighbourhood Social Capital and its Interaction with Individual Level Social Capital on Health}

Giving an overview of existing research on neighbourhood social capital and health is noteasy because studies vary in several theoretical and methodological aspects. A smallnumber of studies have focused on social capital at the neighbourhood-levelusing an eighbourhood of reasonable size and using appropriate analyses tools, such as multi-level methods. Some showed health-improving relationship (Poortinga 2006a, b; Steptoe and Feldman 2001; Wen et al. 2003) while others showed no association (Browning and Cagney 2003; Drukker et al. 2003; Franzini et al. 2005; Ziersch et al. 2005). Some studiesused different kinds of social capital 
Mohnen, S.M., Völker, B., Flap, H., Subramanian, S.V., Groenewegen, P.P. The influence of social capital on individual health: is it the neighbourhood or the network? Social Indicators Research: 2015, 121(1 SI), 195-214

measurements, the results of which were mixed(Drukker et al. 2005; Kavanagh et al. 2006; Snelgrove et al. 2009; Yip et al. 2007).

Carpiano (2007) is, to our knowledge, the only one whose quantitative study shows that theeffects of community social capital on health vary between being positive and negativebecause the access to beneficial resources is not equally distributed. Taken together,existing evidence on neighbourhood social capital and self-rated health is mixed and it isnot clear whether effects of social capital on health are positive, absent or even negative.

Research into the influence of both individual- and neighbourhood-level social capitalon health is scarce.

Poortinga (2006b), Fujisawa et al. (2009), Moore et al. (2011) and De Clercq et al. (2012) found that social capital at both the individual- and the neighbourhood-level ispositively associated with health. Next to significant positive associations between individual-level social capital and self-rated health, Carpiano (2008), Eriksson et al. (2011) and Giordano and Ohlsson (2011) found a positive association between neighbourhood-level social capital and health. However, not all measurements of neighbourhood social capital proved significant.

Kim and Kawachi (2006) are among the very few researchers who have investigated the interaction between the individual- and community-levels social capital.

However, their units on the macro level are municipalities and U.S. states, not neighbourhoods. They have found mixed evidence for the impact of different social capital indicators. While most cross-level interactions between context and individual-level social capital were not significant, they found a positive interaction - an accumulation effect-between individual level social trust and social trust at the context level. Furthermore, they found a negative interaction-a compensation effect - between the involvement of individual-level religious groups and social participation at the context level. Subramanian et al. (2002) used the same data as Kim and Kawachi (2006) and also found a significant accumulation interaction.

For high-trust people, the health-promoting effect of community social trust was significantly greater. To our knowledge, the only study which incorporates crosslevel interactions between neighbourhood- and individual-level social capital, while using neighbourhoods as the contextual level, was done by Carpiano (2008). He found support for the accumulation hypothesis. A limitation is the focus on only one employment group and one city.

\subsection{Relevance of this Study}

This study aims to test whether the effect of neighbourhood social capital is an artefact effect on individual social capital in The Netherlands. In this study we differentiate between contact with neighbours and contact with those who live outside the neighbourhood, while measuring individual social capital. By testing the accumulation and compensation hypotheses, we explore whether neighbourhood social capital is actually a 'public good.' It must be noted that current literature does not give a universal definition of neighbourhood.

The definitions range from being individual perceptions of inhabitants (e.g. Hume et al. 2009; Wen et al. 2003), to those based on neighbourhood networks (Hipp et al. 
Mohnen, S.M., Völker, B., Flap, H., Subramanian, S.V., Groenewegen, P.P. The influence of social capital on individual health: is it the neighbourhood or the network? Social Indicators Research: 2015, 121(1 SI), 195-214

2011) and to statistical and contiguous units, such as postcodes (e.g. Poortinga 2006a). To test our hypotheses, we need to find a definition of neighbourhood, which encompass inter actions within a reasonable spatial extent. In our study, neighbourhoods are relatively small units, delineated via four-digit postal codes. They are areas between 1 and $8 \mathrm{~km}^{2}$ with an average of 2,500-3,000 addresses and approximately 4,000 residents. We used an 'ecometric' aggregation procedure for the measurement of social capital at the community level.

\section{DATA AND METHODS}

\subsection{Data}

We used data from the Dutch 'Housing and Living Survey' (WoON) 2006 and registered information provided by Statistics Netherlands from 1999. The data sets were combined on the basis of four-digit postal codes. The WoON 2006 data $^{3}$ was used to evaluate the physical and social condition of Dutch housing and was collected by the Ministry of Housing, Spatial Planning and Environment(VROM) between August 2005 and March 2006 (Van Huijsduijnen et al. 2007). The data was collected using a two-stage sampling procedure. Firstly, register data were used to sample individuals who were representative of the Dutch population. Secondly, interested municipalities participated in the data collection via an oversampling strategy. The WoON2006 data represents all of the Dutch population aged 18 years or older. The interviews took approximately $40 \mathrm{~min}$. The response rate was $56 \%$. Statistics Netherlands provided register information on socio-demographic data for four-digit postal code areas online. ${ }^{4}$ Questions regarding neighbourhood social capital were only given to the head of the household because it was expected that they would be the only ones able to answer house hold-specific questions. Moreover, some cases were lost because of missing values inindividual and neighbourhood covariates. Of 64,005 participants in the WoON 2006 dataset, we used 53,260 individuals living in 3,273 different neighbourhoods (an average of 16respondents per neighbourhood).

\subsection{Measurements}

\subsubsection{Measurement of Individual-Level Variables}

The dependent variable 'self-perceived health' was measured using the question, 'In general, how good is your health?' Possible answers were '(very good (29\%), good(50\%), fair (12\%). sometimes good, sometimes not good (6 \%) and bad (3\%).' Subjective health is known to be an indicator of morbidity (Simon et al. 2005) and mortality(Idler and Benyamini 1997). The original, highly-skewed scale was dichotomized, with 1representing 'good or very good health', as has been done in other studies (Mohnen et al.

2011; Poortinga 2006b).

The main independent variables at the individual level in this study were the two scales of individual-level social capital. One scale comprised individual-level social capital in the neighbourhood — contact with fellow residents - and the other measured contact with people outside the neighbourhood. Individual-level social capital from neighbours was measured by agreement with two statements: I have a lot of contact with my direct neighbours,' and 'I have a lot of contact with my other 
Mohnen, S.M., Völker, B., Flap, H., Subramanian, S.V., Groenewegen, P.P. The influence of social capital on individual health: is it the neighbourhood or the network? Social Indicators Research: 2015, 121(1 SI), 195-214

neighbours.' Possible answers ranged from 'totally disagree' (1) to 'totally agree' (5). For the analyses, we created a dichotomous variable: sum scores larger than or equal to 8 were re-coded as 1 and all other values were re-coded as 0 . Therefore, those who generally agreed on both statements are perceived as having social capital in their network.

The second scale for individual-level social capital considered possible contact to friends and family members: 'How often do you have contact with friends or with people you know very well (including phone contact)?' ' and 'How often do you have contact with one or more family member (not in the same household and including phone contact)?'The response categories for both questions were 'almost never' (1), 'less than once per month' (2), 'once per month' (3), '2 or 3 times per month' (4) and 'once a week (5)'. We created a dichotomous variable by re-coding the value 5 as 1 and recoding all others values as 0 . Although it was not explicitly asked, we assumed that 'other contact' would most likely with those located outside the neighbourhood. From the Dutch network data, we know that $90 \%$ of all friends are not neighbours (The Survey on the Social Networks of the Dutch, 2007-n = 604 Dutch individuals). A Canadian study showed that only 4-7 \%of respondents live in the same neighbourhood as their non-household relatives (Wellman1979).

We further used socio-demographic variables that have been shown to be important fora multilevel analyses of health: Sex was coded as a dummy variable, age was measured in years and centred at an average of 51.2 years, and ethnic background was categorised as either Dutch, 2nd generation Western, 2nd generation NonWestern, 1st generation Western or 1st generation Non-Western. Three indicators of social status were added: education, employment and income. Education was measured as the 'highest school degree so far achieved' at the time of questioning. We used five categories ranging from 1(primary school or less) to 5 (university degree). Employment groups included self-employed individuals and employees, those without a paid job, pensioners, recipients of social benefits and students (at any kind of school or university). Of all 'WoON 2006'respondents, $93.8 \%$ gave direct information on their own income and the income of their partner. For the remaining $6.2 \%$ (3.4 \% tax information; $2.8 \%$ imputation of tax information),income information was collected by the Dutch tax office and added to the dataset (Van Huijsduijnen et al. 2007). Income was measured by an 'equivalent monthly household income.' This variable took into account all kinds of income (per household),including social benefits, pensions, and salaries. It was calculated by weighting ${ }^{5}$ the costs of children and the benefits of sharing a household (Siermann et al. 2004). For the analyses, income was divided into 10 categories: $1=$ negative income (i.e. income of entrepreneurs who made investments greater than their income), 2 = income between $€ 0$ and $€ 599.99$,values between 3 and 9 indicate incremental income differences of $€ 300$ and $10=€ 2,700$ plus per month. Category 5 $(€ 1,200.00-€ 1,499.99)$ was the median and the reference category. Furthermore, in previous neighbourhood studies, 'home ownership' has been shown to be an important condition for some questions (Harpham 2008; Ross and Jang2000). Home owners, in contrast to renters, usually invest more in the physical and social order of their neighbourhood (DiPasquale and Glaeser 1999). We included this variable to mark the difference between 'owner' and 'renter.' Finally, 'years of residence' was included at the individual level to control the length of influence of the context neighbourhood. 
Mohnen, S.M., Völker, B., Flap, H., Subramanian, S.V., Groenewegen, P.P. The influence of social capital on individual health: is it the neighbourhood or the network? Social Indicators Research: 2015, 121(1 SI), 195-214

The question was straightforward: 'How long have you been living at this address?' In the analysis, we constructed four categories: (1) 0-5 years (2) 6-15 years, (3)1625 years, and (4) 26 and more years. We controlled 'presence of young children in the household' because it strengthens the association between neighbourhood social capital and health (Mohnen et al. 2013). We distinguished between people who live in households with children aged $\backslash 12$ years and those without. We chose this age because these children are still in primary school, which is usually close to their homes.

\subsubsection{Measurement of Neighbourhood-Level Variables}

The key independent variable was neighbourhood social capital. Neighbourhood social capital was measured using three questions about the neighbourhood in which the respondent lived:

1. Whether people in the neighbourhood know each other?

2. Whether neighbours are kind to each other?

3. Whether there is a friendly and sociable atmosphere in the neighbourhood? The response categories were 'totally agree,' 'agree,' 'neutral,' 'do not agree,' and 'totally do not agree,' on a range from 1 to 5.

Other neighbourhood characteristics which we measured were included as three covariates: The percentage of people in the lowest income quintile in a neighbourhood (Statistics Netherlands) was considered as a covariate. Income can come from work or one's own company, social benefits, pensions and financial support for students. We added the aggregated information on individual perception regarding home maintenance. The WoON 2006 participants were asked whether their house was in bad repair. Response categories were recorded on a 5-point scale ranging from 'I totally agree' (1) to 'I totally do not agree' (5). Higher values indicate better home maintenance, at least from the resident's point of view. The degree of urban density of the municipality was taken into account (Statistics Netherlands). The coding of this variable is based on the number of addresses per $\mathrm{km}^{2}$. It was a five-point scale, where higher values indicate greater urban density.

\subsubsection{Ecometric-Based Measurement of Neighbourhood Social Capital}

To gain contextual information from individual data, individual information was aggregated to the higher level of the neighbourhood. The most straightforward aggregation procedure is to calculate the average for each neighbourhood or the standard deviation of the items measured at the individual level (Cummins et al. 2005; Kawachi and Subramanian2006; Kawachi et al. 2008; Stafford et al. 2003). However, this procedure does not solve a number of problems.

Firstly, variables measuring neighbourhood social capital are based on individual perception and it is likely that this perception is influenced by the characteristics of the respondent. For example, older people might compare neighbourhood social capital with what they remember from former times and therefore report systematically lower scores of social capital in their current neighbourhood than younger people. Secondly, because the number of respondents differs per neighbourhood, the reliability of the aggregated measurement, in our case the social capital measurement, also differs between the neighbourhoods. Thirdly, the items that measure social capital are not independent of each other. 
Mohnen, S.M., Völker, B., Flap, H., Subramanian, S.V., Groenewegen, P.P. The influence of social capital on individual health: is it the neighbourhood or the network? Social Indicators Research: 2015, 121(1 SI), 195-214

In summary, one wants an approach that accounts for individual differences in response to certain items, as well as for the differences in the number of respondents on which the estimation is based and for the dependency between the items measuring social capital.

One method that meets these requirements is the recently-developed ecometrics approach(Mujahid et al. 2007; Raudenbush and Sampson 1999; Nyqvist et al. 2013). This is similar to the approach employed in earlier work (Mohnen et al. 2011). This approach employs a three-level model: one level is for neighbourhoods, one for individuals and one for the items measuring social capital.

We adjusted for eight individual characteristics that might influence the perception of neighbourhood social capital: sex, age, education, income, employment status, homeownership, years of residence and self-rated health. The ecometric model accounts for differences in the number of respondents per neighbourhood by shrinking deviating neighbourhoods with smaller numbers of respondents to the general average (Hox 2002).

The interdependence of individual responses to items is handled by ecometrics via the separate level for the social capital items in the multilevel model.

In the first step of the analysis, neighbourhood social capital is estimated using this three-level model. The residuals of the neighbourhood social capital measurement (i.e. the part that cannot be attributed to individual response patterns) constitute the social capital measurement for the final analyses in the second step, where the hypotheses are tested. In this second step, the ecometric-based social capital measurement is used as an independent variable in a two-level logistic model, with a binary indicator for health as the dependent variable.

The model estimating neighbourhood social capital is as follows:

$$
Y_{i j k}=\gamma_{000}+\sum_{m=1}^{2} \alpha_{m} D_{m i j k}+\sum_{q=1}^{8} \delta_{q} X_{q j k}+v_{00 k}+u_{0 j k}+e_{i j k}
$$

$\mathrm{Y}_{\mathrm{ijk}}$ is the response to item $\mathrm{i}$ of person $\mathrm{j}$ in neighbourhood $\mathrm{k}, \gamma_{000}$ is the grand mean of neighbourhood social capital, $\mathrm{m}$ is the number of social capital variables (three in total; one serves as reference), $\mathrm{D}$ are item dummies, $\mathrm{q}$ is the number of individual level adjusters (8 in total), $\mathrm{X}$ are the control variables, $\mathrm{v}$ is the neighbourhood variance, $\mathrm{u}$ is the individual variance, and e is the item variance.

The most important parameters are the neighbourhood-level residuals, v, which indicate the degree to which the social capital of neighbourhood $k$ differs from the grand mean, $\gamma_{000}$. These residuals constitute the neighbourhood social capital measure. Positive values indicate higher-than-average levels of neighbourhood social capital.

The reliability of ecometric scales depends on the variance at all three levels, i.e. the items nested within respondents and the respondents nested within neighbourhoods (Hox, 2002). The reliability of neighbourhood social capital is estimated by: 


$$
\lambda_{k}=\frac{\sigma^{2}}{\sigma^{2}+\frac{\tau^{2}}{J_{k}}+\frac{\omega^{2}}{n J_{k}}}
$$

$\sigma^{2}$ is the variance in neighbourhood level; $\tau^{2}$ is the variance between individuals perneighbourhood; and $\omega^{2}$ is the variance between the items. $\mathrm{J}_{\mathrm{k}}$ is the number of individuals in the neighbourhood ${ }^{\mathrm{k}}$. Finally, $\mathrm{n}$ is the number of items that measure neighbourhood social capital. The average reliability of our ecometric-based neighbourhood social capital measurement is 0.702 .

The intra class correlation (ICC) for the indication of clustering was calculated by the following formula for a multilevel logistic model:

$$
I C C=\frac{\sigma^{2}}{\sigma^{2}+3.29}
$$

$\sigma^{2}$ is the variance in neighbourhood level (Snijders and Bosker 1999, p. 224).

Table 1 shows the correlation of individual variables and Table 2 the neighbourhood variables. Interestingly, frequency of contact with neighbours and frequency of contact with others (usually non-residents) are not highly correlated. In rural areas, people have more neighbourhood-level social capital than people in urban areas. Table 3 shows descriptive statistics for the individual and neighbourhood variables.

\subsection{Analytic Strategy}

To test our hypotheses we estimated logistic multilevel models. Each regression is performed with relevant characteristics at the individual and neighbourhood level (as in earlier work this is done Mohnen et al. 2011, 2012, 2013). To test the main effects of individualand neighbourhood level social capital, we performed analyses containing social capital variables at both levels (summarised in Table 4, models 13). Next, we tested hypotheses 3to 4 by estimating models that include both individual-level and neighbourhood-level social capital measurements and their interactions (Table 4, model 4-6 and Fig. 1). For all multivariate analyses we used the statistical software package SAS Enterprise guide 4.3(proc glimmix dist = binary, link = logit).

\section{[TABLE 1][TABLE 2]}

\section{RESULTS}

The intra class correlation shows that health is clustered in Dutch neighbourhoods. In the empty model (not presented), the intra class correlation is $3.51 \%$. Hypothesis 1 states that neighbourhood social capital is positively associated with health and that it is independent of the level of a person's individual social capital. Models 1 to 3 in Table 4 show that the effect of neighbourhood-level social capital is independent of the two types of individuallevel social capital.

Hypothesis 2 stated that individual social capital is positively associated with an individual's health and is independent of neighbourhood social capital. Table 4, 
Mohnen, S.M., Völker, B., Flap, H., Subramanian, S.V., Groenewegen, P.P. The influence of social capital on individual health: is it the neighbourhood or the network? Social Indicators Research: 2015, 121(1 SI), 195-214

model 1shows that a high level of contact with neighbours is positively associated with self-rated health when controlling neighbourhood-level social capital $(\mathrm{B}=$ 0.068, p B 0.01).

Table 4, model 2 shows that, independent of neighbourhood social capital, weekly contact with friends and family is positively associated with self-rated health $(\mathrm{B}=$ 0.208,p B 0.001). Table 4, model 3 shows that, independent of neighbourhood social capital, only weekly contact with other network members is positively related with health. This partly supports hypothesis 2 .

Hypotheses 3 predicted a compensating effect of neighbourhood- and individuallevel social capital on health. Table 4, model 4 shows that the combined effect of contact with neighbours and neighbourhood social capital is not associated with health. Hence, a lack of contact with neighbours cannot be compensated by neighbourhood social capital. Table 4,model 5 shows that the combined effect of weekly contact with friends or family and neighbourhood social capital is significantly associated with health $(B=-0.298$, p B 0.05). Figure 1 shows a graphical representation of model $5 .{ }^{6}$ People who have contact with family and friends less than once a week (presumably mainly outside the neighbourhood) are less likely to be in good health than people with frequent contact.

However, their disadvantages can be compensated by a high level of neighbourhood social capital. When contact to friends and family is less often than weekly, one standard deviation(SD) increase in neighbourhood social capital is associated with an $8.4^{7}$ increase in the log odds of good health. The effect on one SD increase in neighbourhood social capitalis 3.2 times higher $^{8}$ for people who have contact with family and friends less than once a week than for those with more. Table 4, model 6 shows that the compensation effect of neighbourhood social capital for a lack of contact with family and friends holds $(\mathrm{B}=0.289$, p B 0.05$)$ even if it is controlled for neighbour contact at the individual level.

\section{[TABLE 3]}

Hypothesis 3 is supported when individual social capital is measured with contacts to friends and family.

Hypotheses 4 predicted an accumulating effect of neighbourhood- and individuallevel social capital on health. Figure 1 shows that the effect of individual-level social capital is stronger than the neighbourhood social capital effect. Independent of the neighbourhood where one lives, people with high individual-level social capital report better health.

Hypothesis 4 is not supported because of the very small effect of neighbourhood social capital on health for people with high individual-level social capital, measured along side contact to friends and family.

\section{[TABLE 4] [FIGURE 1]}

\section{DISCUSSION}

This study contributes to the understanding of the relationship between neighbourhood social capital and individual health. Many previous studies have shown that both neighbourhood-and individual-level social capital are positively associated with health, but only rarely have both types of social capital been combined in one analysis. In a similar way to other studies (De Clercq et al. 2012; 
Mohnen, S.M., Völker, B., Flap, H., Subramanian, S.V., Groenewegen, P.P. The influence of social capital on individual health: is it the neighbourhood or the network? Social Indicators Research: 2015, 121(1 SI), 195-214

Fujisawa et al. 2009; Moore et al. 2011;Poortinga 2006b), we have shown that an individuals' health is positively associated with the social capital of their neighbourhood as well as the individual level in the Netherlands.

As in these other studies, we measured neighbourhood social capital with neighbourhood related questions regarding the social cohesion in a neighbourhood. When non-neighbourhoodrelated, social capital variables (e.g. trust in general or participation in a non- neighbourhood related organisation) were used, neighbourhood social capital showed no association with health (Eriksson et al. 2011; Giordano and Ohlsson 2011).

In this study, we categorised individual social capital into frequent contact with neighbours and weekly face-to-face or telephone contact with friends or non-house hold family members; both showed to be positively associated with health. Frequent contact with neighbours was not significantly associated with health when also controlling neighbourhood social capital and contact with friends and non-household family members.

Our findings regarding contacts outside the neighbourhood are in line with those of Mooreet al. (2011), who studied a number of social capital characteristics and their influence on health. Notably, a high level of diversity in the external network, indicated by a position generator measurement for individual-level social capital (Lin 2001), corresponded with better health.

In Moore's study (op. cit.), as well as in all aforementioned studies, cross-level interaction between individual- and neighbourhood-level social capital were not analysed. This is, however, necessary to test the accumulation and compensation hypotheses. An exception is Carpiano's (2008) study on caregivers in urban neighbourhoods of the U.S.

city Los Angeles, C.A. Contact with neighbours (he called this 'attachment to the neighbourhood') had a negative interaction effect with 'social leverage' on selfperceived health. Social leverage is a neighbourhood-level variable and measured by asking the question: 'How often do you and other people in the neighbourhood ask each other advice about personal things such as child rearing or job openings?'. As described in the background section, Carpiano defines the social capital of a neighbourhood by the number of networks of inhabitants. Our study, however, describes neighbourhood social capital as there sources produced by a close-knit community with shared norms. In addition, we included sub-urban and rural neighborhoods in our analysis, while Carpiano's study had only urban neighbourhoods in the sample.

Besides showing two independent effects of individual- and neighbourhood-level social capital, our findings support the compensation hypothesis. While controlling for contact with neighbours, people with less frequent contact with friends and family are more likely to report good health when they live in neighbourhoods with high rather than low social capital. The neighbourhood community seems to be able to support an unconnected resident with its health-related resources. These findings are in line with Klinenberg's(2002) results on the survival chances of an isolated elderly man in Chicago during the heatwave of 1995. In the Netherlands, it has been shown that elderly people often have less individual-level social capital with friends and more with relatives (Van Tilburg 1998).

Unfortunately, family size is declining in modern societies (Office for National Statistics1999). When life expectancy increases and social networks for the elderly 
Mohnen, S.M., Völker, B., Flap, H., Subramanian, S.V., Groenewegen, P.P. The influence of social capital on individual health: is it the neighbourhood or the network? Social Indicators Research: 2015, 121(1 SI), 195-214

decreases, neighbourhood social capital might become even more relevant for the health of elderly. It is a task for future researchers to formulate and test hypotheses on the conditions under which compensation or accumulation of social capital may occur. So far, we have found no evidence for accumulation. This is in line with Kim and Kawachi (2006) and Subramanianet al. (2002) whose studies were on larger units rather than small-area neighbourhoods.

Three limitations in our study should be mentioned. Firstly, as with most research conducted in this area, our analysis cannot rule out the endogeneity problem, i.e. social capital becomes correlated with the regression error term. Given that the estimation does'not account for endogeneity of social capital, the results should be treated as correlation between social effects and health outcomes rather than a causal effect of social capital. Wedo not know whether people reported good health because of high social capital or if their good health gave them greater opportunity to build up social capital (also known as reversed causality). We do know, however, that the neighbourhood perception of social capital was not biased by health because we applied the ecometric procedure to measure neighbourhood social capital. The second limitation of this research is that willingness to participate in the study could have been higher for people with greater social capital and/orare in good health. People in neighbourhoods with low social capital were probably more sceptical of strangers and therefore less likely to participate in the survey. Unfortunately, response rates by neighbourhood are not available. Moreover, dichotomization of the dependent variable might lead to loss of information. However, the results of the robustness test (simple regression with health as a continuous variable and an ordered logistic regression) were very similar to the analyses presented in the article and caused no difference to the conclusions.

These limitations aside, our findings advance the empirical literature on neighbourhood social capital and health in two ways. Firstly, we measured social capital by the ecometric procedure. This resulted in a measurement at an appropriate level while the interdependence of individual responses to items is handled via the separate level for the social capital items in the multilevel model (Raudenbush and Sampson 1999; Mujahid et al.

2007). Secondly, our study was not restricted to a single city; $82 \%$ of all Dutch neighbourhoods were taken into account.

Future research might be improved with the use of smaller administrative units, as done in this study. The effect of neighbourhood social capital on individual health is probably underestimated because researchers have used neighbourhood unit measurements that are too large. Neighbourhoods were measured with four-digit postcodes. On average, 4,000people live in these small areas. Smaller units such as Statistics Netherlands' neighbourhoods might be more homogeneous. Unfortunately, information at this level was not available for this study which means that neighbourhood effects might have been underestimated.

Future research that takes Statistics Netherlands' neighbourhoods into account will probably find the effect of neighbourhood social capital stronger here because the smaller units are more homogeneous. However, it is interesting that even when using an imperfect measurement, such as a four-digit postcode, to determine the impact of neighbourhood social capital, it still had clear effects on health when individual-level social capital is controlled. The most important finding of our study is that neighbourhood- and individual-level social capital are both positively associated with 
Mohnen, S.M., Völker, B., Flap, H., Subramanian, S.V., Groenewegen, P.P. The influence of social capital on individual health: is it the neighbourhood or the network? Social Indicators Research: 2015, 121(1 SI), 195-214

health and that they are relatively independent of one another. Hence, it is not the case that one needs social ties at the individual level to benefit from neighbourhoodlevel social capital. In other words, individual-level social capital does not necessarily provide access to neighbourhood-level social capital.

Now that the link between neighbourhood social capital and self-rated health is established, the practical implications of this finding may be elaborated on. While social capital at the individual level has already been established as a healthimproving factor, theidea of community social capital, in particular, neighbourhood social capital, and its stimulation is a new one to public health. Coleman suggested that '[...] most forms of social capital are created or destroyed as by-products of other activities.' (Coleman 1988,p. 118) Therefore, arranging a neighbourhood soccer field, street festival, BBQ or social meeting point is not always intended to link people and create social capital at the neighbourhood level but can potentially have that effect. Our study cannot advise policy makers to implement particular interventions to increase neighbourhood social capital.

Further research is needed into the long-term effects of neighbourhood social capital. This is because the time of exposure matters in the relationship between neighbourhood social capital and individual health (Mohnen et al. 2013). A study of the pathways is also needed in order to understand how neighbourhood social capital 'gets under the skin' of inhabitants(Taylor et al. 1997). Lastly, field experiments that intend to increase neighbourhood social capital have to be evaluated. At this point, our findings are useful for policy makers and neighbourhood workers who often have to argue the point that neighbourhood work matters. The difficult part is not only arguing that (in this time of modernisation and globalisation) the context neighbourhood matters but also that the people living in the neighbourhoods and their interrelations matter.

Acknowledgments We would like to thank the Data Archiving and Networked Services (DANS) formaking our free use of WoON 2006 possible. We thank Dr. Wouter Steenbeek (Netherlands Institute for the Study of Crime and Law Enforcement, Amsterdam) for his help with applying ecometrics. The article benefited from comments by Interuniversity Center for Social Science Theory and Methodology (ICS)colleagues at 'Forum days'.

\section{NoTES:}

${ }^{1}$ The idea that something new develops from a community is also expressed in the phrase, 'The whole is more than the sum of its parts' (King 2005, p. 96; Von Ehrenfels 1890). This expression of the German' Gestalt'-theory is based on research on 'melody'. A melody is more than the sum of notes. In the context of a neighbourhood this means that the whole is a close-knit community with shared norms and access to community resources, whereas the sum would only be the number of inhabitants and interactions between them are not taken into account.

${ }^{2}$ An exception is Portes (1998) who believed that social capital would harm the health of the individual.

${ }^{3}$ Data can be found online at http://easy.dans.knaw.nl/ui/home with a search for urn:nbn:nl:ui:13-tcv-dug. Accessed in January 2013.

${ }^{4}$ Statistics Netherlands: http://statline.cbs.nl/statweb/. Accessed in January 2013.

${ }^{5}$ If no information on the number of the household members was available $(n=7,630)$, we used the non-weighted monthly household income. 
Mohnen, S.M., Völker, B., Flap, H., Subramanian, S.V., Groenewegen, P.P. The influence of social capital on individual health: is it the neighbourhood or the network? Social Indicators Research: 2015, 121(1 SI), 195-214

${ }^{6}$ We used http://www.jeremydawson.co.uk/2-way_with_binary_moderator.xls. The intercept was 1.274 .

${ }^{7} 8.39 \%=\operatorname{EXP}\left(\left(0.177^{\star} 0\right) ?\left(0.403^{\star} 0,2\right)-\left(0.177^{\star} 0 \star 0,2\right)\right)-\operatorname{EXP}\left(\left(0.177^{\star} 0\right)+\left(0.403^{\star} 0\right)-\right.$ $(0.298 * 0 * 0))$.

${ }^{8} 3.2$ times $=(8.39 \% / 2.53 \%)$ while $2.53 \%==\operatorname{EXP}\left(\left(0.177^{\star} 1\right)+\left(0.403^{\star} 0,2\right)-\left(0.298^{\star} 1 * 0.2\right)\right)$ $-\operatorname{EXP}\left(\left(0.177^{\star} 1\right)+\left(0.403^{\star} 0\right)-\left(0.298^{\star} 1^{*} 0\right)\right)$.

\section{REFERENCES}

Browning, C. R., \& Cagney, K. A. (2003). Moving beyond poverty: Neighborhood structure, social processes, and health. Journal of Health and Social Behavior, 44, 552-571.

Carpiano, R. M. (2007). Neighborhood social capital and adult health: An empirical test of a Bourdieu-based model. Health and Place, 13, 639-655.

Carpiano, R. M. (2008). Actual or potential neighborhood resources and access to them: Testing hypotheses of social capital for the health of female caregivers. Social Science and Medicine, 67, 568-582.

Coleman, J. S. (1988). Social capital in the creation of human capital. American Journal of Sociology, 94,S95-S120.

Coleman, J. S. (1990). Foundations of social theory. Cambridge, MA: Harvard University Press.

Cummins, S., Macintyre, S., Davidson, S., \& Ellaway, A. (2005). Measuring neighbourhood social and material context: Generation and interpretation of ecological data from routine and non-routine sources. Health \& Place, 11, 249-260.

De Clercq, B., Vyncke, V., Hublet, A., Elgar, F. J., Ravens-Sieberer, U., Currie, C., et al. (2012). Social capital and social inequality in adolescents' health in 601 Flemish Communities: A multilevel analysis.

Social Science and Medicine, 74, 202-210.

Diez-Roux, A. V., \& Mair, C. (2010). Neighborhoods and Health. Annals of the New York Academy of Sciences, 1186, 125-145.

Diez-Roux, A. V., Nieto, F. J., Muntaner, C., Tyroler, H. A., Comstock, G. W., Shahar, E., et al. (1997).

Neighborhood environments and coronary heart disease: A multilevel analysis. American Journal of Epidemiology, 146, 48-63.

DiPasquale, D., \& Glaeser, G. (1999). Incentives and social capital: Are homeowners better citizen? Journal of Urban Economics, 45, 354-384.

Drukker, M., Buka, S. L., Kaplan, C., McKenzie, K., \& Van Os, J. (2005). Social capital and young adolescents' perceived health in different sociocultural settings. Social Science and Medicine, 61,185-198.

Drukker, M., Kaplan, C., Feron, F., \& Van Os, J. (2003). Children's health-related quality of life, neighbourhood socio-economic deprivation and social capital. A contextual analysis. Social Science and Medicine, 57, 825-841.

Eriksson, M., Ng, N., Weinehall, L., \& Emmelin, M. (2011). The importance of gender and conceptualization for understanding the association between collective social capital and health: A multilevel analysis from Northern Sweden. Social Science and Medicine, 73, 264-273.

Franzini, L., Caughy, M., Spears, W., \& Eugenia Fernandez Esquer, M. (2005). Neighborhood economic conditions, social processes, and self-rated health in low-income neighborhoods in Texas: A multilevel latent variables model. Social Science and Medicine, 61, 1135-1150.

Fujisawa, Y., Hamano, T., \& Takegawa, S. (2009). Social capital and perceived health in Japan: Anecological and multilevel analysis. Social Science and Medicine, 69, 500-505.

Giordano, G. N., \& Ohlsson, H. (2011). Social capital and health-Purely a question of context? Health \&Place, 17, 946-953.

Hammer, M. (1983). 'Core' and 'extended' social networks in relation to health and illness. Social Science and Medicine, 17, 405-411.

Harpham, T. (2008). The measurement of community social capital through surveys. In I. Kawachi, S. 
Mohnen, S.M., Völker, B., Flap, H., Subramanian, S.V., Groenewegen, P.P. The influence of social capital on individual health: is it the neighbourhood or the network? Social Indicators Research: 2015, 121(1 SI), 195-214

V. Subramanian, \& D. Kim (Eds.), Social capital and health (pp. 51-62). New York, NY: SpringerScience and Business Media.

Hendryx, M. S., Ahern, M. M., Lovrich, N. P., \& McCurdy, A. H. (2002). Access to health care and community social capital. Health Services Research, 37, 85-101.

Hipp, J. R., Faris, R. W., \& Boessen, A. (2011). Measuring 'neighborhood': Constructing network neighborhoods.

Social Networks, 34, 128-140.

House, J. S. (1981). Work stress and social support. Menlo Park, CA: Addison-Wesly.

Hox, J. J. (2002). Multilevel analysis: Techniques and applications. Mahwah, NJ: Lawrence Erlbaum Associates.

Hume, C., Jorna, M., Arundell, L., Saunders, J., Crawford, D., \& Salmon, J. (2009). Are children's perceptions of neighbourhood social environments associated with their walking and physical activity? Journal of Science and Medicine in Sport, 12, 637-641.

Hystad, P., \& Carpiano, R. M. (2010). Sense of community-belonging and health-behaviour change inCanada. Journal of Epidemiology and Community Health.

doi:10.1136/jech.2009.103556.

Idler, E. L., \& Benyamini, Y. (1997). Self-rated health and mortality: A review of twenty-seven community studies. Journal of Health and Social Behavior, 38, 21-37.

Kavanagh, A. M., Bentley, R., Turrell, G., Broom, D. H., \& Subramanian, S. V. (2006). Does gender modify associations between self rated health and the social and economic characteristics of local environments? Journal of Epidemiology and Community Health, 60, 490.

Kawachi, I., \& Subramanian, S. V. (2006). Measuring and modeling the social and geographic context of trauma: A multilevel modeling approach. Journal of Traumatic Stress, 19, 195-203.

Kawachi, I., Subramanian, S. V., \& Kim, D. (2008). Social capital and health. New York, NY: Springer.

Kim, D., \& Kawachi, I. (2006). A multilevel analysis of key forms of community- and individual-level social capital as predictors of self-rated health in the United States. Journal of Urban Health, 83,813-826.

King, D. B. (2005). Max Wertheimer and Gestalt theory. New Brunswick, NJ: Transaction Publisher.

Klinenberg, E. (2002). Heat wave: A social autopsy of disaster in Chicago. Chicago, IL: University of Chicago Press.

Lin, N. (2001). Social capital: A theory of social structure and action. Cambridge: Cambridge UniversityPress.

Lin, N., Simeone, R. S., Ensel, W. M., \& Kuo, W. (1979). Social support, stressful life events, and illness: Amodel and an empirical test. Journal of Health and Social Behavior, 20, 108119.

Maas, J., Van Dillen, S. M. E., Verheij, R. A., \& Groenewegen, P. P. (2008). Social contacts as a possible mechanism behind the relation between green space and health. Health \& Place, 15, 586-595.

Mohnen, S. M., Groenewegen, P. P., Völker, B., \& Flap, H. (2011). Neighborhood social capital and individual health. Social Science and Medicine, 72, 660-667.

Mohnen, S. M., Volker, B., Flap, H., \& Groenewegen, P. P. (2012). Health-related behavior as a mechanism behind the relationship between neighborhood social capital and individual health—A multilevel analysis. BMC Public Health, 12. doi:10.1186/1471-245812-116.

Mohnen, S. M., Volker, B., Flap, H., Subramanian, S. V., \& Groenewegen, P. P. (2013). You have to be there to enjoy it? Neighborhood social capital and health. The European Journal of Public Health,23(1), 33-39.

Moore, S., Bockenholt, U., Daniel, M., Frohlich, K., Kestens, Y., \& Richard, L. (2011). Social capital and core network ties: A validation study of individual-level social capital measures and their association with extra- and intra-neighborhood ties, and self-rated Health. Health \& Place, 17, 536-544.

Moore, S., Haines, V., Hawe, P., \& Shiell, A. (2006). Lost in translation: A genealogy of the "social capital"concept in public health. Journal of Epidemiology and Community Health, $60,729-734$ 
Mohnen, S.M., Völker, B., Flap, H., Subramanian, S.V., Groenewegen, P.P. The influence of social capital on individual health: is it the neighbourhood or the network? Social Indicators Research: 2015, 121(1 SI), 195-214

Mujahid, M. S., Diez-Roux, A. V., Morenoff, J. D., \& Raghunathan, T. (2007). Assessing the measurement properties of neighborhood scales: From psychometrics to ecometrics. American Journal of Epidemiology,165, 858-867.

Nauenberg, E., Laporte, A., \& Shen, L. (2011). Social capital, community size and utilization of health services: A lagged analysis. Health Policy, 103, 38-46.

Nyqvist, F., Nyga ${ }^{\circ}$ rd, M., \& Steenbeek, W. (2013). Social capital and self-rated health amongst older peoplein Western Finland and Northern Sweden: A multi-level analysis. International Society of Behavioral Medicine,. doi:10.1007/s12529-013-9307-0.

Office for National Statistics. (1999). Changes in fertility and family sizes in Europe. Population Trends, 95,33-40.

Poortinga, W. (2006a). Do health behaviors mediate the association between social capital and health? Preventive Medicine, 43, 488-493.

Poortinga, W. (2006b). Social relations or social capital? Individual and community health effects of bonding social capital. Social Science and Medicine, 63, 255-270.

Portes, A. (1998). Social capital: Its origins and applications in modern sociology. Annual Review of Sociology, 24, 1-24.

Putnam, R. D., Leonardi, R., \& Nanetti, R. Y. (1993). Making democracy work-Civic traditions in modern Italy. Princeton, NJ: Princeton University Press.

Raudenbush, S. W., \& Sampson, R. J. (1999). Ecometrics: Toward a science of assessing ecological settings, with application to the systematic social observation of neighborhoods. Sociological Methodology, 29,1-41.

Ross, C. E., \& Jang, S. J. (2000). Neighborhood disorder, fear, and mistrust: The buffering role of social ties with neighbors. American Journal of Community Psychology, 28, 401420.

Shaw, J. H. (2006). Food deserts: Towards the development of a classification. Geografiska Annaler: Series B, Human Geography, 88, 231-247.

Siermann, C. L. J., Van Teeffelen, P. J. J., \& Urlings, L. J. M. (2004). Equivalentie factoren 1995-2000[Equivalence factors 1995-2000]. Heerlen: Statistics Netherlands.

Simon, J. G., De Boer, J. B., Joung, I. M. A., Bosma, H., \& Mackenbach, J. P. (2005). How is your health in general? A qualitative study on self-assessed health. European Journal of Public Health, 15, 200-208.

Snelgrove, J. W., Pikhart, H., \& Stafford, M. (2009). A multilevel analysis of social capital and self-rated health: Evidence from the British household panel survey. Social Science and Medicine, 68,1993-2001.

Snijders, T. A. B., \& Bosker, R. J. (1999). Multilevel Analysis: An Introduction to Basic and Advanced Multilevel Modeling. Thousand Oaks, CA: Sage.

Stafford, M., Bartley, M., Sacker, A., Marmot, M., Wilkinson, R., Boreham, R., et al. (2003). Measuring the social environment: Social cohesion and material deprivation in English and Scottish neighbourhoods.

Environment and Planning A, 35, 1459-1475.

Steptoe, A., \& Feldman, P. J. (2001). Neighborhood problems as sources of chronic stress: Development of a measure of neighborhood problems, and associations with socioeconomic status and health. Annals of Behavioral Medicine, 23, 177-185.

Stockdale, S. E., Wells, K. B., Tang, L., Belin, T. R., Zhang, L., \& Sherbourne, C. D. (2007). The importance of social context: Neighborhood stressors, stress-buffering mechanisms, and alcohol, drug, and mental health disorders. Social Science and Medicine, 65, 18671881.

Subramanian, S. V., Kim, D. J., \& Kawachi, I. (2002). Social trust and self-rated health in US communities: A multilevel analysis. Journal of Urban Health: Bulletin of the New York Academy of Medicine, 79,S21-S34.

Subramanian, S. V., Lochner, K. A., \& Kawachi, I. (2003). Neighborhood differences in social capital: A compositional artifact or a contextual construct? Health \& Place, 9, 33-44.

Sundquist, K., Eriksson, U., Kawakami, N., Skog, L., Ohlsson, H., \& Arvidsson, D. (2011). Neighborhood walkability, physical activity, and walking behavior: The Swedish Neighborhood and Physical Activity(SNAP) Study. Social Science and Medicine, 72, 12661273. 
Mohnen, S.M., Völker, B., Flap, H., Subramanian, S.V., Groenewegen, P.P. The influence of social capital on individual health: is it the neighbourhood or the network? Social Indicators Research: 2015, 121(1 SI), 195-214

Taylor, S. E., Repetti, R. L., \& Seeman, T. (1997). Health psychology: What is an unhealthy environment and how does it get under the skin? Annual Review of Psychology, 48, 411447.

Taylor, S. E., \& Seeman, T. E. (1999). Psychosocial resources and the SES-health relationship. Annals of the New York Academy of Sciences, 896, 210-225.

Tijhuis, M. A. R., Flap, H. D., Foets, M., \& Groenewegen, P. P. (1995). Social support and stressful events in two dimensions: Life events and illness as an event. Social Science and Medicine, 40, 1513-1526.

Uchino, B. N., Cacioppo, J. T., \& Kiecolt-Glaser, J. K. (1996). The relationship between social support and physiological processes: A review with emphasis on underlying mechanisms and implications for health. Psychological Bulletin, 119, 488-531.

Van Huijsduijnen, J. H., Van Til, R. J., Verhoog, E., Gopal, K., Ferment, B., \& Van Galen, J. (2007). WoOn2006 documentation of the housing demand survey-Module housing market [Dutch Language]. Delft: The Netherlands Ministry of Housing, Spatial Planning and Environment.

Van Tilburg, T. (1998). Losing and gaining in old age: Changes in personal network size and social support in a four-year longitudinal study. Journal of Gerontology, 53B, S313-S323.

Von Ehrenfels, C. (1890). über Gestaltqualitäten [on the qualities of form]. Vierteljahrsschrift Für Wissenschaftliche Philosophie, 14, 249-292.

Wellman, B. (1979). The community question: The intimate networks of East Yorkers. The American Journal of Sociology, 84, 1201-1231.

Wen, M., Browning, C. R., \& Cagney, K. A. (2003). Poverty, affluence, and income inequality: Neighborhood economic structure and its implications for health. Social Science and Medicine, 57, 843-860.

Yip, W., Subramanian, S. V., Mitchell, A. D., Lee, D. T. S., Wang, J., \& Kawachi, I. (2007). Does social capital enhance health and well-being? Evidence from rural China. Social Science and Medicine, 64,35-49.

Ziersch, A. M., Baum, F. E., MacDougall, C., \& Putland, C. (2005). Neighbourhood life and social capital: The implications for health. Social Science and Medicine, 60, 71-86. 
Mohnen, S.M., Völker, B., Flap, H., Subramanian, S.V., Groenewegen, P.P. The influence of social capital on individual health: is it the neighbourhood or the network? Social Indicators Research: 2015, 121(1 SI), 195-214

\section{TABLES AND FiguRES}

Table 1 Correlation of individual variables (Spearman's rho) $\left(\mathrm{n}_{\mathrm{i}}=53,260\right)$

\begin{tabular}{|c|c|c|c|c|c|c|c|c|c|c|c|}
\hline & 1. & 2. & 3. & 4. & 5. & 6. & 7. & 8. & 9. & 10. & 11. \\
\hline 1. Self-perceived health & 1.000 & - & - & - & - & - & - & - & - & - & - \\
\hline 2. Sex & $-0.081^{* * *}$ & 1.000 & - & - & - & - & - & - & - & - & - \\
\hline 3. Age & $-0.301^{* *}$ & $0.056^{* *+}$ & 1.000 & - & - & - & - & - & - & - & - \\
\hline $\begin{array}{l}\text { 4. Ethnic background }{ }^{a} \\
(1=\text { Dutch })\end{array}$ & $0.038^{* *}$ & -0.006 & $0.143^{* *}$ & 1.000 & - & - & - & - & - & - & - \\
\hline 5. Education ${ }^{\mathrm{b}}$ & $0.270^{* *}$ & $-0.114^{* *}$ & $-0.330^{* *}$ & $-0.009^{*}$ & 1.000 & - & - & - & - & - & - \\
\hline $\begin{array}{l}\text { 6. Occupation }{ }^{2} \\
(1=\text { employed })\end{array}$ & 0.301 ** & $-0.161^{* *}$ & $-0.466^{* *}$ & $0.025^{* *}$ & $0.283^{* *}$ & 1.000 & - & - & - & - & - \\
\hline 7. Income & $0.225^{* *}$ & $-0.094^{* *}$ & $-0.022^{* *}$ & $0.137^{* *}$ & $0.399^{* *}$ & $0.294^{* * *}$ & 1.000 & - & - & - & - \\
\hline 8. Home ownership & $-0.224^{* *}$ & $0.074^{* * *}$ & $0.101^{* *}$ & $-0.151^{* *}$ & $-0.295^{4 *}$ & $-0.258^{* *}$ & $-0.465^{* *}$ & 1.000 & - & - & - \\
\hline 9. Years of residence & $-0.120^{* *}$ & $0.020^{* *}$ & $0.538^{* *}$ & $0.122^{* *}$ & $-0.186^{* *}$ & $-0.190^{* *}$ & $0.034^{* *}$ & $-0.067^{* *}$ & 1.000 & - & - \\
\hline $\begin{array}{l}\text { 10. Young children } \\
\text { in household }\end{array}$ & $0.151^{* * *}$ & 0.007 & $-0.403^{* * *}$ & $-0.097^{* * *}$ & $0.146^{* * *}$ & $0.238^{* * *}$ & $0.053^{* * *}$ & $0.169^{* * *}$ & $-0.240^{* * *}$ & 1.000 & - \\
\hline 11. Contact with neighbours & 0.008 & -0.020 & $0.066^{* * *}$ & $0.034^{* * 4}$ & $-0.037^{* *}$ & $-0.004^{*}$ & $0.019 * *$ & $-0.103^{* *}$ & $0.092^{* *}$ & $0.075^{* * *}$ & 1.000 \\
\hline $\begin{array}{l}\text { 12. Contact with friends } \\
\text { and family }\end{array}$ & $0.115^{* *}$ & $0.052^{* *}$ & $-0.140^{* *}$ & $0.054^{* *}$ & $0.124^{* *}$ & $0.093^{* *}$ & $0.094^{* *}$ & $-0.103^{* *}$ & $-0.061^{* *}$ & $0.052^{* *}$ & $0.093^{* *}$ \\
\hline
\end{tabular}

${ }^{*} p \leq 0.05 ;{ }^{* *} p \leq 0.01 ;{ }^{* * *} p \leq 0.001$

a This variable has no order. It was transformed to a dichotomous variable to calculate Spearman's tho

${ }^{b}$ Used as metric variable

Table 2 Correlation coefficients of neighbourhood variables (Pearson) $\left(\mathrm{n}_{\mathrm{j}}=3,273\right)$

\begin{tabular}{lllll}
\hline & 1. & 2. & 3. & 4. \\
\hline 1. Neighbourhood social capital & 1.000 & - & - & - \\
2. Percentage in lowest income quintile & $0.139^{* * *}$ & 1.000 & - & - \\
3. Urban density of municipality & $-0.562^{* *}$ & $-0.238^{* * *}$ & 1.000 & - \\
4. Neighbourhood home maintenance & $0.305^{* *}$ & 0.008 & $0.189^{* *}$ & 1.000 \\
\hline
\end{tabular}

$* p \leq 0.05 ; * * p \leq 0.01 ; * * * p \leq 0.001$ 
Mohnen, S.M., Völker, B., Flap, H., Subramanian, S.V., Groenewegen, P.P. The influence of social capital on individual health: is it the neighbourhood or the network? Social Indicators Research: 2015, 121(1 SI), 195-214

Table 3 Descriptive statistics for individual- and neighbourhood-level variables, data source: WoON 2006 $\left(\mathrm{n}_{\mathrm{i}}=53,260, \mathrm{n}_{\mathrm{j}}=3,273\right)$

\begin{tabular}{|c|c|c|c|c|}
\hline & Range & Mean & SD & Percent \\
\hline \multicolumn{5}{|l|}{ Individual-level controls } \\
\hline \multicolumn{5}{|l|}{ Self-perceived health } \\
\hline Not good $(0)$ & & & & 21.0 \\
\hline Good or better (1) & & & & 79.0 \\
\hline \multicolumn{5}{|l|}{ Sex } \\
\hline Man (1) & & & & 45.1 \\
\hline Woman (2) & & & & 54.9 \\
\hline Age in years & $18-103$ & 51.2 & 17.2 & \\
\hline \multicolumn{5}{|l|}{ Ethnic background } \\
\hline Native Dutch (1) & & & & 83.3 \\
\hline 2nd generation Western ( 2 ) & & & & 3.9 \\
\hline 2nd generation Non-Western (3) & & & & 1.0 \\
\hline lst generation Western (4) & & & & 4.3 \\
\hline 1st generation Non-Western (5) & & & & 7.5 \\
\hline Education primary education & & & & 13.0 \\
\hline Junior secondary vocational education & & & & 16.9 \\
\hline Junior general secondary education & & & & 13.9 \\
\hline $\begin{array}{l}\text { Senior general secondary education, } \\
\text { university preparatory education } \\
\text { and senior secondary vocational education }\end{array}$ & & & & 30.0 \\
\hline University degree or other forms of higher education & & & & 26.3 \\
\hline \multicolumn{5}{|l|}{ Occupation } \\
\hline No job (1) & & & & 5.6 \\
\hline Self-employed or employee (2) & & & & 48.3 \\
\hline Pensioner (3) & & & & 26.3 \\
\hline Welfare recipient (4) & & & & 10.4 \\
\hline Student (5) & & & & 9.4 \\
\hline \multicolumn{5}{|l|}{ Income $^{\mathrm{a}}$} \\
\hline Negative income (1) & & & & 0.5 \\
\hline $0-599 €(2)$ & & & & 1.6 \\
\hline $600-899 €(3)$ & & & & 11.4 \\
\hline $900-1,199 €(4)$ & & & & 16.8 \\
\hline $1,200-1,499 \in(5)$ & & & & 17.9 \\
\hline $1,500-1,799 \in(6)$ & & & & 15.7 \\
\hline $1,800-2,099 \in(7)$ & & & & 12.1 \\
\hline $2,100-2,399 €(8)$ & & & & 8.5 \\
\hline $2,400-2,699 €(9)$ & & & & 5.2 \\
\hline $2,700 €$ and more $(10)$ & & & & 10.0 \\
\hline \multicolumn{5}{|l|}{ Home ownership } \\
\hline Owner (1) & & & & 54.3 \\
\hline Renter (2) & & & & 45.7 \\
\hline \multicolumn{5}{|l|}{ Years of residence } \\
\hline $0-5$ years $(1)$ & & & & 29.8 \\
\hline
\end{tabular}


Mohnen, S.M., Völker, B., Flap, H., Subramanian, S.V., Groenewegen, P.P. The influence of social capital on individual health: is it the neighbourhood or the network? Social Indicators Research: 2015, 121(1 SI), 195-214

Table 3 continued

\begin{tabular}{|c|c|c|c|c|}
\hline & Range & Mean & SD & Percent \\
\hline $6-15$ years $(2)$ & & & & 34.9 \\
\hline $16-25$ years $(3)$ & & & & 16.6 \\
\hline$\geq 26$ years $(4)$ & & & & 18.7 \\
\hline \multicolumn{5}{|l|}{ Young children in the household } \\
\hline Yes (1) & & & & 20.6 \\
\hline No $(0)$ & & & & 79.4 \\
\hline \multicolumn{5}{|l|}{ Contact with neighbours } \\
\hline Only rarely $(0)$ & & & & 60.2 \\
\hline Frequently (1) & & & & 39.8 \\
\hline \multicolumn{5}{|l|}{ Contact with friends and family } \\
\hline Less than weekly contact (0) & & & & 27.3 \\
\hline At least weekly contact (1) & & & & 72.7 \\
\hline \multicolumn{5}{|l|}{ Neighbourhood level } \\
\hline Neighbourhood social capital & -0.78 to 0.46 & -0.10 & 0.20 & \\
\hline Percentage in lowest income quintile & $11.29-71.43$ & 24.80 & 3.70 & \\
\hline Neighbourhood home maintenance & $1-5$ & 3.90 & 0.30 & \\
\hline Urban density of municipality & $1-5$ & 2.70 & 1.30 & \\
\hline
\end{tabular}

\footnotetext{
${ }^{a}$ In the analyses, categories 1 and 2 are combined. A category for missing values was included in the analysis $(\mathrm{n}=93)$

$\mathrm{n}_{\mathrm{i}}=\mathrm{n}$ on individual level, $\mathrm{n}_{\mathrm{j}}=\mathrm{n}$ on neighbourhood level
}

Table 4 Multilevel logistic regression of the combined effects of individual- and neighbourhood-level social capital on individual health (odds ratios, $95 \%$ confidence interval in parentheses)

\begin{tabular}{|c|c|c|c|c|c|c|}
\hline$(\mathrm{ni}=53,260, \mathrm{nj}=3,273)$ & Model 1 & Model 2 & Model 3 & Model 4 & Model 5 & Model 6 \\
\hline Intercept (standard error) & $1.354(0.241)^{8 * 8}$ & $1.257(0.241)^{888}$ & $1.246(0.241)^{888}$ & $1.362(0.241)^{88 *}$ & $1.274(0.241)^{8 * 8}$ & $1.267(0.242)^{888}$ \\
\hline \multicolumn{7}{|l|}{ Individual-level social capital } \\
\hline Frequent contact with neighbours & $0.068(0.025)^{88}$ & & $0.043(0.025)$ & $0.057(0.027)^{*}$ & & $0.037(0.027)$ \\
\hline $\begin{array}{l}\text { At least weekly contact with } \\
\text { friends and family }\end{array}$ & & $0.208(0.026)^{888}$ & $0.202(0.026)^{8 * 8}$ & & $0.177(0.029)^{8 * 8}$ & $0.172(0.029)^{8 * 8}$ \\
\hline \multicolumn{7}{|l|}{ Neighbourhood-level social capital } \\
\hline \multicolumn{7}{|l|}{ Interactions } \\
\hline $\begin{array}{l}\text { Macro social capital } \times \text { contact } \\
\text { with neighbours }\end{array}$ & & & & $-0.120(0.117)$ & & $-0.080(0.118)$ \\
\hline $\begin{array}{l}\text { Macro social capital } \times \text { contact } \\
\text { with friends and family }\end{array}$ & & & & & $-0.298(0.120)^{8}$ & $-0.289(0.121)^{8}$ \\
\hline Variance in neighbourhood level & $0.017 * 8$ & $0.017^{* 8}$ & $0.017^{8 *}$ & $0.017^{* 8}$ & $0.017^{88}$ & $0.017^{* 8}$ \\
\hline Intraclass correlation (\%) & 0.51 & 0.51 & 0.51 & 0.51 & 0.51 & 0.51 \\
\hline
\end{tabular}

$\mathrm{n}_{\mathrm{i}}=\mathrm{n}$ on individual level, $\mathrm{n}_{\mathrm{j}}=\mathrm{n}$ on neighbourhood level; ${ }^{*} p \leq 0.05 ; * 8 p \leq 0.01 ; * 8 * p \leq 0.001$. All models were controlled for sex, age, ethnic background, education, employment, income, presence of young children in the household, home ownership, and years of residence at the individual level and for lowest income quintile, urban density of municipality, and home maintenance at the neighbourhood level 
Mohnen, S.M., Völker, B., Flap, H., Subramanian, S.V., Groenewegen, P.P. The influence of social capital on individual health: is it the neighbourhood or the network? Social Indicators Research: 2015, 121(1 SI), 195-214

Fig. 1 Interaction of individual(friends and family) and neighbourhood-level social capital on self-rated health

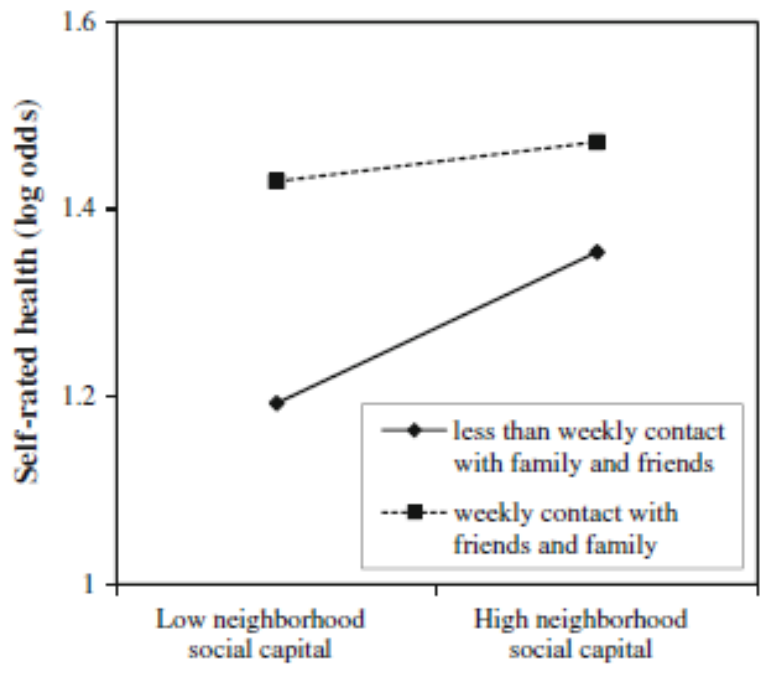

